\title{
SISTEM INFORMASI MANAJEMEN NAZWA WEDDING ORGANIZER BERBASIS WEB
}

\author{
Restika Putri Andini \\ Program Studi Sistem Informasi, Fakultas Teknik dan Ilmu Komputer \\ Universitas Islam Indragiri (UNISI) \\ Jl. Provinsi No.01 Tembilahan Hulu, Indragiri Hilir, Riau - Indonesia \\ Email: restikaputriiii@gmail.com, dwiyuliprasetyo@gmail.com, usmanovsky13411@gmail.com
}

\begin{abstract}
Until now, Nazwa Wedding Organizer does not have a special application that is used as a means of wedding services in the data management process, where the process is still using a ledger, starting from recording, searching for tenant data, ordering, paying and making reports. This method has several drawbacks, namely long transactions, errors can occur, tenants who are far from the wedding organizer services must come directly to the location to make orders and payments. Therefore we need a software development process in the form of a wedding organizer nazwa management information system which aims as a means for tenants who want to make transactions with wedding organizer services both when they want to make orders and payments, and as a means for wedding services to input. , search for tenant data and report generation. The processes carried out are data collection in the form of observations, interviews and literature studies, system analysis, system design or design, system implementation and system testing or testing. The system development method used is the waterfall method, while the analysis method used is the pieces method which can be a reference in building a web-based wedding organizer nazwa management information system. The modeling system used is a web-based UML (Unified Modeling Language) modeling with PHP (Hypertext Preprocessor) programming language and MYSQL database. The Nazwa wedding organizer management information system that has been built functions according to User needs, namely in inputting tenant data, searching for tenant data, managing order data, managing payment data, and managing booking reports. With the Nazwa wedding organizer management information system, it is hoped that it can be useful as a means for the wedding party and the tenant in conducting transactions so that time becomes more effective.
\end{abstract}

Keywords: Web-Based Management Information System, Wedding Organizer Application, Nazwa Wedding Organizer Tembilahan.

\section{PENDAHULUAN}

Pertumbuhan teknologi informasi $(\mathrm{TI})$ serta ilmu pengetahuan pada masa globalisasi sudah bekerjasama dengan banyak bidang ilmu yang lain serta memasuki ke seluruh bidang. Sehingga pemakaian teknologi informasi sangat di butuh hkan buat menolong menggapai tujuan- tujuan tertentu dari suatu organisasi [1].

Menurut Kadir dalam [2] Sistem informasi ialah beberapa komponen (manusia, komputer, teknologi informasi, serta prosedur kerja), terdapat suatu yang diproses (data jadi informasi), serta dimaksudkan dapat menggapai sesuatu target ataupun tujuan.

Sistem Informasi Manajemen ialah rangkaian terorganisasi dari beberapa bagian/ komponen yang secara bersama-sama berperan ataupun bergerak menciptakan informasi yang digunakan dalam manajemen perusahaan [3].

Nazwa Wedding Organizer merupakan sebuah usaha yang bergerak di bidang jasa yang beralamatkan di Jl. Telaga Biru Parit 11 Depan Capella Honda. Nazwa Wedding Organizer menawarkan beberapa macam jenis paket dari mulai harga terendah sampai dengan harga tertinggi. Tentu saja setiap paket memiliki fasilitas yang berbeda-beda. 
Menurut Kasali, Rhenald dalam [4] Wedding Organizer merupakan sesuatu jasa Event Organizer yang berperan secara individu membantu calon pengantin serta keluarga dalam perencanaan serta supervisi penerapan rangkaian kegiatan acara pernikahan dengan agenda serta bayaran yang telah ditetapkan. Ada pula kinerja dari wedding organizer dibagi jadi 3 sesi, ialah sesi konsultasi awal, sesi konsultasi lanjutan, serta sesi penerapan kegiatan.

Menurut Agus Hariyanto dalam [5] Website bisa dimaksud sebagai kumpulan halaman yang menunjukkan informasi berupa data teks, data foto, data animasi, suara, video serta gabungan dari seluruhnya, baik yang bersifat statis ataupun dinamis yang membentuk satu rangkaian bangunan yang saling terpaut, dimana masing-masingnya akan dihubungkan dengan jaringan-jaringan halaman (hyperlink).

Saat ini teknologi banyak berubah dari yang masih belum terkomputerisasi ke sistem yang telah terkomputerisasi sebagai sarana dalam melakukan suatu kegiatan menjadi lebih efektif. Melihat banyak nya perubahan yang terjadi, tidak seperti di Nazwa Wedding Organizer yang saat ini pada proses mengelola datanya masih melalui buku besar, mulai dari pencatatan, pencarian data penyewa, pemesanan, pembayaran serta pembuatan laporannya. Cara tersebut memiliki beberapa kekurangan yaitu transaksi yang lama dan penyewa yang berada jauh dari jasa wedding organizer tersebut harus datang langsung ketempat untuk melakukan pemesanan dan pembayaran.

Oleh karena itu penelitian ini bertujuan untuk membangun sebuah inovasi sebagai sarana untuk penyewa yang ingin melakukan transaksi dengan jasa wedding organizer baik itu saat ingin melakukan pemesanan maupun pembayaran, kemudian sebagai sarana pihak jasa wedding dalam melakukan pencatatan, pencarian data penyewa dan pembuatan laporan, dengan menggunakan metode analisa pieces yang dapat menjadi acuan dalam membangun sebuah sistem informasi manajemen wedding organizer.

\section{TINJAUAN PUSTAKA}

Berikut ini adalah penelitian yang telah dilakukan dan memiliki korelasi yang searah dengan penelitian yang akan dibahas dalam skripsi ini. Dalam upaya menyempurnakan penelitian maka perlu dilakukan Kajian Literatur, diantaranya yaitu:

Tabel 1. Penelitian Terdahulu

\begin{tabular}{|c|c|c|c|c|}
\hline No & Peneliti & Judul & Perbandingan & Hasil \\
\hline 1 & $\begin{array}{l}\text { Misbahul khoir } \\
\text { dan Dimas } \\
\text { Abisono } \\
\text { Punkastyo dari } \\
\text { Jurusan Teknik } \\
\text { Informatika, } \\
\text { Fakultas Teknik, } \\
\text { Universitas } \\
\text { Pamulang, } \\
\text { Tangerang } \\
\text { Selatan (2021) }\end{array}$ & $\begin{array}{l}\text { Rancang } \\
\text { Bangun } \\
\text { Sistem } \\
\text { Informasi } \\
\text { Manajemen } \\
\text { Jasa } \\
\text { Pernikahan } \\
\text { Berbasis } \\
\text { Website pada } \\
\text { Toko Maula } \\
\text { Wedding [7]. }\end{array}$ & $\begin{array}{l}\text { Pada penelitian } \\
\text { ini juga } \\
\text { melakukan } \\
\text { penelitian } \\
\text { berbasis web. } \\
\text { Namun, pada } \\
\text { penelitian ini } \\
\text { dibuat } \\
\text { menggunakan } \\
\text { framework } \\
\text { Codeigniter. }\end{array}$ & $\begin{array}{l}\text { Hasil dari penelitian ini adalah } \\
\text { untuk menghasilkan sebuah } \\
\text { sistem informasi manajemen } \\
\text { berbasis website agar dapat } \\
\text { membantu Toko Maula Wedding } \\
\text { di dalam mengelola dan } \\
\text { mempromosikan usahanya, serta } \\
\text { sebagai sarana pembeli/penyewa } \\
\text { di dalam mengakses informasi } \\
\text { dan melakukan transaksi } \\
\text { pemesanan produk pada Toko } \\
\text { Maula Wedding. }\end{array}$ \\
\hline 2 & $\begin{array}{lr}\text { Difia } & \text { Agustin, } \\
\text { Alexius } & \text { Ulan } \\
\text { Bani } & \text { dan } \\
\text { Fauziyah } & \text { dari } \\
\text { Program } & \text { Studi } \\
\text { Sistem } & \\
\text { Informasi, } & \\
\end{array}$ & $\begin{array}{l}\text { Perancangan } \\
\text { Sistem } \\
\text { Informasi Jasa } \\
\text { Wedding } \\
\text { Organizer } \\
\text { pada CV. } \\
\text { Boganesia } \\
\end{array}$ & $\begin{array}{l}\text { Pada penelitian } \\
\text { ini hanya } \\
\text { melakukan satu } \\
\text { kali pengujian } \\
\text { yaitu blackbox, } \\
\text { sementara pada } \\
\text { penelitian yang }\end{array}$ & $\begin{array}{l}\text { Hasil dari penelitian ini adalah } \\
\text { sebuah sistem informasi sebagai } \\
\text { sarana penyewa dalam } \\
\text { melakukan pemesanan wedding } \\
\text { organizer melalui web serta } \\
\text { sebagai sarana pihak CV. }\end{array}$ \\
\hline
\end{tabular}




\begin{tabular}{|c|c|c|c|c|}
\hline & $\begin{array}{l}\text { Fakultas IImu } \\
\text { Komputer, } \\
\text { Universitas Bung } \\
\text { Karno, Indonesia } \\
(2020)\end{array}$ & $\begin{array}{l}\text { Jaya Berbasis } \\
\text { Web [8]. }\end{array}$ & $\begin{array}{l}\text { penulis lakukan } \\
\text { melakukan } \\
\text { pengujian } \\
\text { blackbox dan } \\
\text { kuesioner. }\end{array}$ & $\begin{array}{l}\text { Bo } \\
\text { dat }\end{array}$ \\
\hline 3 & $\begin{array}{l}\text { Misbahul khoir } \\
\text { dan Dimas } \\
\text { Abisono } \\
\text { Punkastyo dari } \\
\text { Jurusan Teknik } \\
\text { Informatika, } \\
\text { Fakultas Teknik, } \\
\text { Universitas } \\
\text { Pamulang, } \\
\text { Tangerang } \\
\text { Selatan(2021) }\end{array}$ & $\begin{array}{l}\text { Rancang } \\
\text { Bangun } \\
\text { Sistem } \\
\text { Informasi } \\
\text { Manajemen } \\
\text { Jasa } \\
\text { Pernikahan } \\
\text { Berbasis } \\
\text { Website pada } \\
\text { Toko Maula } \\
\text { Wedding [7]. }\end{array}$ & $\begin{array}{l}\text { Pada penelitian } \\
\text { ini juga } \\
\text { melakukan } \\
\text { penelitian } \\
\text { berbasis web. } \\
\text { Namun, pada } \\
\text { penelitian ini } \\
\text { dibuat } \\
\text { menggunakan } \\
\text { framework } \\
\text { Codeigniter. }\end{array}$ & $\begin{array}{l}\text { Hasil dari penelitian ini adalah } \\
\text { untuk menghasilkan sebuah } \\
\text { sistem informasi manajemen } \\
\text { berbasis website agar dapat } \\
\text { membantu Toko Maula Wedding } \\
\text { di dalam mengelola dan } \\
\text { mempromosikan usahanya, serta } \\
\text { sebagai sarana pembeli/penyewa } \\
\text { di dalam mengakses informasi } \\
\text { dan melakukan transaksi } \\
\text { pemesanan produk pada Toko } \\
\text { Maula Wedding. }\end{array}$ \\
\hline
\end{tabular}

\section{METODE PENELITIAN}

\subsection{Metode Pengumpulan Data}

Pada penelitian ini, peneliti mengumpulkan data untuk mengetahui berbagai permasalahan yang terjadi dilapangan, sehingga peneliti bisa menemukan pokok-pokok permasalahan yang ada dengan menggunakan berbagai metode sebagai berikut:

Pada tahap pertama pengumpulan data peneliti melakukan observasi (pengamatan). Dalam metode ini, peneliti melakukan observasi di Nazwa Wedding Organizer yang beralamat di Jl. Telaga Biru Parit 11 depan Capella Honda Tembilahan pada tanggal 12 November 2020 sebagai langkah awal untuk mengetahui permasalahan apa yang terjadi dan mengamati langsung bagaimana sistem yang sedang berjalan.

Tahap kedua pengumpulan data peneliti melakukan wawancara, wawancara dilakukan pada tanggal 27 November 2020. Dalam metode ini, peneliti melakukan tanya jawab (wawancara) langsung kepada Elvianti selaku pemilik Nazwa Wedding Organizer yang dimana wawancara tersebut dilakukan di lokasi Nazwa Wedding Organizer untuk mengetahui proses yang sedang berjalan dan meminta persetujuan untuk dibuatnya sebuah sistem informasi yang berguna untuk mengorganisir data-data yang ada pada Nazwa Wedding Organizer. Pada tanggal 30 November 2020 peneliti kembali melakukan wawancara pada pemilik Nazwa Wedding Organizer disini peneliti meminta data yang di perlukan yang berkaitan dengan penelitian yang akan dibuat.

Tahap ketiga pengumpulan data yaitu studi pustaka. Tahap ini peneliti mencari sumbersumber tulisan dan mempelajari referensi-referensi berupa jurnal yang berkaitan dengan penelitian ini, guna untuk melengkapi penelitian dan menambah informasi yang diperlukan.

\subsection{Metode Pengembangan Sistem}

Metode pengembangan sistem yang diterapkan pada penelitian ini adalah dengan pengembangan metode waterfall. Menurut Pressman dalam [9]. Metode waterfall merupakan model pengembangan sistem informasi yang sistematik dan sekuensial. Metode Waterfall memiliki tahapan-tahapan yaitu Requirements analysis and definitio, System and software design, Implementation and unit testing, Integration and system testing, Operation and maintenance, sebagaimana akan dijelaskan di bawah ini : 


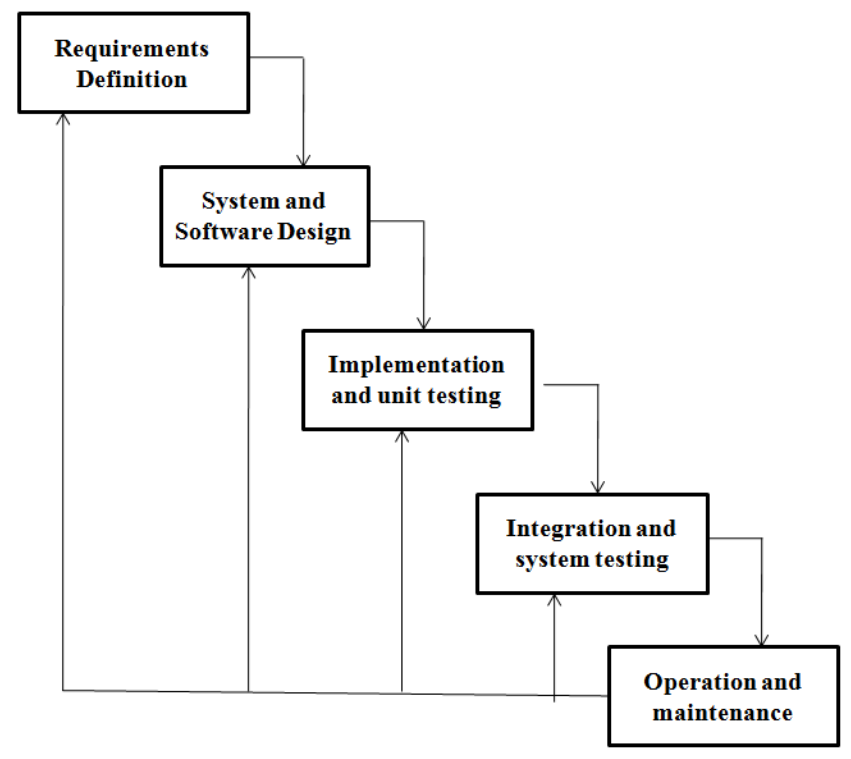

Gambar 1. Metode Pengembangan Sistem Waterfall

1. Requirements analysis and definition

Dalam tahap ini pengembang sistem memerlukan komunikasi yang ditujukan untuk memahami perangkat lunak yang diharapkan oleh pengguna dan batasan perangkat lunak tersebut. Informasi ini di dapat melalui wawancara kepada ibu Elvianti selaku pemilik Nazwa Wedding Organizer. Kemudian informasi dianalisis untuk mendapatkan data yang dibutuhkan oleh pengguna.

2. System and software design

Pada tahap ini desain metode yang digunakan adalah UML yang menggunakan diantaranya : use case diagram, activity diagram, sequence diagram, class diagram, data model, dan deployment diagram. System and software design merupakan tahapan perancangan sistem mengalokasikan kebutuhan-kebutuhan sistem baik perangkat keras maupun perangkat lunak dengan membentuk arsitektur sistem secara keseluruhan. Perancangan perangkat lunak melibatkan identifikasi dan penggambaran abstraksi sistem dasar perangkat lunak dan hubungannya.

3. Implementation and unit testing

Implementation and unit testing dalam tahap ini merupakan perancangan perangkat lunak direalisasikan sebagai serangkaian program atau unit program. Pengujian melibatkan verifikasi bahwa setiap unit memenuhi spesifikasinya. Tahap ini peneliti menggunakan bahasa pemrograman PHP dengan database MySQL.

4. Integration and system testing

Integration and system testing merupakan unit-unit individu program atau program digabung dan diuji sebagai sebuah sistem lengkap untuk memastikan apakah sesuai dengan kebutuhan perangkat lunak atau tidak. Setelah pengujian, perangkat lunak dapat dikirimkan ke customer. Pada tahap ini peneliti menggunakan pengujian dengan Black-Box Test, White Box Test dan kuesioner. Dengan adanya pengujian dapat dilihat kekurangan-kekurangan sistem yang dibangun sehingga peneliti bisa memperbaiki sistem yang dibangun sesuai dengan kebutuhan pengguna. $95 \%$ kebergunaan sistem yang dibangun untuk dimanfaatkan oleh pengguna.

5. Operation and maintenance

Operation and maintenance biasanya (walaupun tidak selalu), tahapan ini merupakan tahapan yang paling panjang. Sistem dipasang dan digunakan secara nyata. Maintenance melibatkan pembetulan kesalahan yang tidak ditemukan pada tahapan-tahapan sebelumnya, meningkatkan implementasi dari unit sistem, dan meningkatkan layanan sistem sebagai kebutuhan baru. 


\section{HASIL DAN PEMBAHASAN}

Bagian ini menyajikan hasil penelitian dari awal Sistem Informasi Manajemen Nazwa Wedding Organizer Berbasis Web yang terdiri dari hasil analisa, hasil desain, hasil implementasi, hasil verification dan hasil pemeliharaan.

\subsection{Metode Analysis PIECES}

Adapun hasil Analisa dengan menggunakan Metode PIECES memiliki enam variable penilaian dalam melakukan evaluasi yaitu:

Metode PIECES adalah metode analisis sebagai dasar untuk memperoleh pokok-pokok permasalahan yang lebih spesifik. Metode PIECES memiliki enam variable penilaian dalam melakukan evaluasi yaitu performance (kinerja), Informations (informasi), economy (ekonomi), control (pengendalian), efficiency (efesiensi), service (pelayanan) [10]. Analisa perancangan sistem ini digunakan untuk mengambil keputusan apabila sistem ini mempunyai masalah atau sudah tidak berfungsi secara baik, dan hasilnya digunakan sebagai dasar untuk memperbaiki sistem. Adapun analisa sistem yang peneliti gunakan sebagai berikut: Metode PIECES memiliki enam variable penilaian dalam melakukan evaluasi yaitu :

1. Performance (Kinerja)

Analisa kinerja pada sistem yang lama masih kurang effektif karena dalam proses pengelolaan data, pencatatan, pencarian data penyewa, pemesanan, pembayaran serta pembuatan laporannya di tuliskan pada buku besar. Untuk sistem baru yang berbasis web sudah efektif dan dapat mempersingkat waktu serta sebagai sarana proses pengelolaan data, penginputan data penyewa, pencarian data penyewa, pemesanan, pembayaran serta pembuatan laporannya.

2. Information (Informasi)

Pada sistem yang lama informasi mengenai data penyewa hanya ada di buku besar, dan penyewa ketika ingin mendapatkan informasi mengenai wedding organizer harus datang langsung kelokasi, serta belum ada informasi rekap laporan mengenai data penyewa sehingga hal ini dinilai kurang efektif. Pada sistem yang baru penyewa bisa mendapatkan informasi dan melakukan pemesanan serta pembayaran melalui website, kemudian Admin dapat mengupdate data produk dan mencetak rekap laporan data pemesanan yang berkaitan dengan wedding organizer.

3. Economy (Ekonomi)

Pada sistem yang lama data- data mengenai wedding organizer masih di catat di buku besar, hal ini akan memakai banyak kertas sehingga akan terjadinya tumpukan- tumpukan kertas dan terjadinya pemborosan kertas. Dari sistem yang baru memberikan penghematan waktu dan penghematan biaya dalam pembelian kertas saat ingin mencatat data penyewa serta membuat laporan karena kemungkinan terjadinya kesalahan sangat kecil.

4. Control (Pengendalian)

Sistem pengendalian masih sangat lemah, ini terlihat dari pengelolaan data pada wedding organizer yang masih tuliskan pada buku besar, yang kemungkinan akan terjadi tumpukan kertas dan kehilangan data-data penting yang berkaitan dengan wedding organizer. Sehingga dalam pencarian data dan pembuatan laporannya harus membuka kembali catatan data yang tertulis pada buku besar. Pada sistem yang baru dapat di gunakan sebagai sarana untuk melakukan pencarian data secara otomatis dan pencetakan laporan sesuai dengan kebutuhan, serta untuk menghindari kehilangan data-data penting akibat tumpukan kertas.

5. Eficiency (Efesiensi)

Sistem lama masih belum efisien karena setiap data penyewa yang masuk harus di catat di buku, kemudian dalam pencarian datanya dan pembuatan laporan pemesanan membutuhkan waktu yang lama, tetapi dengan sistem yang baru cukup menginput data dan mencari data melalui sistem yang ada maka laporan data akan muncul secara otomatis, cepat dan tidak membutuhkan waktu yang lama. 
6. Service (Pelayanan)

Dari proses pelayanan cukup baik namun membutuhkan waktu yang cukup lama. Contohnya ketika ada beberapa penyewa yang melakukan pemesanan secara bersamaan sehi ngga membutuhkan waktu yang cukup lama dikarenakan pihak wedding harus mencari data pemesanan penyewa yang sudah memesan lebih dahulu mulai dari tanggal resepsi dan lain nya, agar tidak ada bentrok jadwal pemesanan antara penyewa satu dengan penyewa lainnya, tetapi dengan sistem yang baru pihak wedding organizer dapat menginput kan data agenda acara sesuai jadwal yang ada, kemudian penyewa dapat melihat agenda acara pada wedding organizer sebelum melakukan pemesanan, hal ini dilakukan untuk menghindari terjadinya bentrok tanggal.

\subsection{Use Case Diagram}

Use case diagram menggambarkan fungsionalitas yang diharapkan dari sebuah sistem. Yang ditekankan adalah "apa" yang diperbuat sistem, dan bukan "bagaimana". Berdasarkan penjelasan tersebut, maka dapat digambarkan use case diagram Sistem Informasi Manajemen Nazwa Wedding Organizer seperti Gambar 2 berikut :

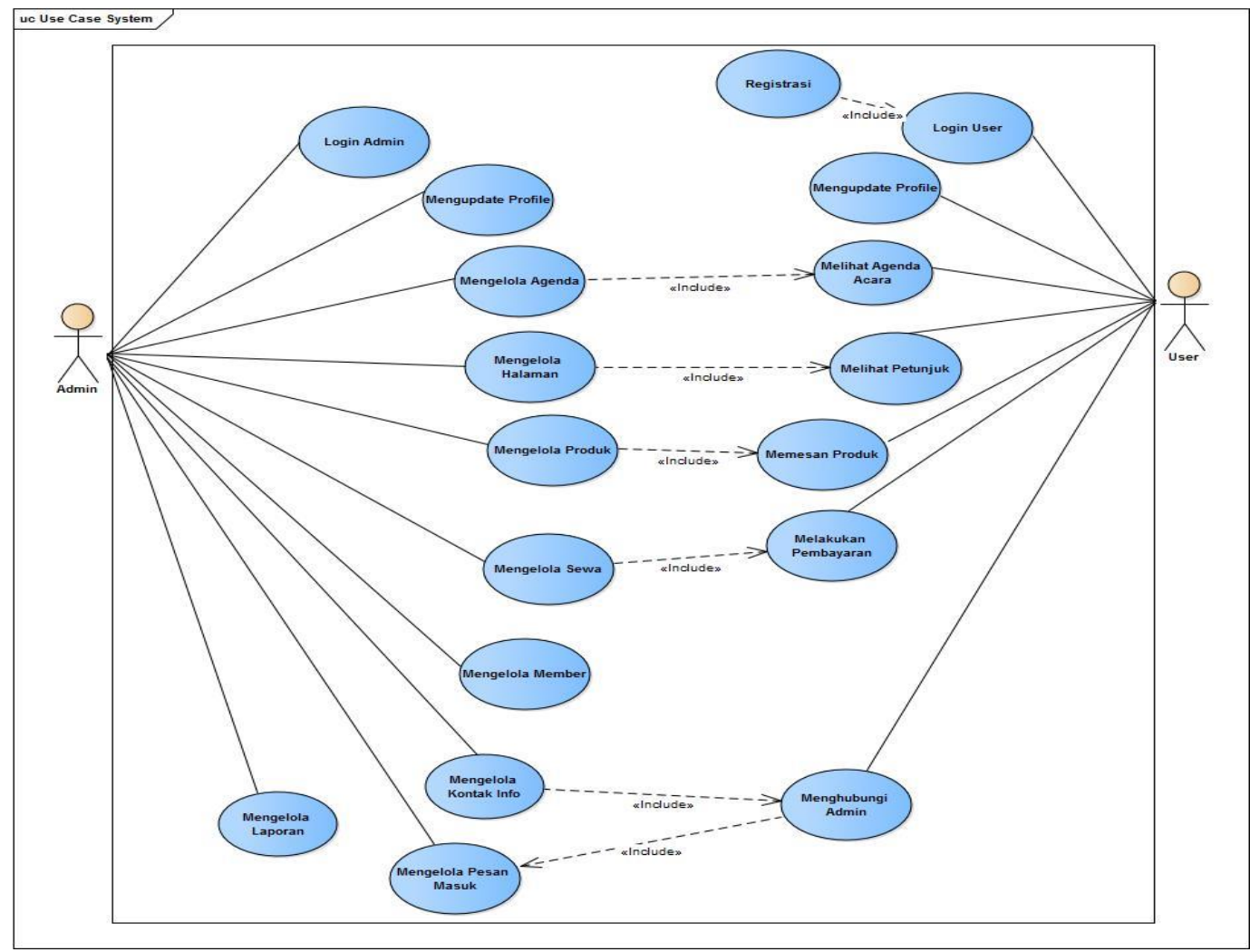

Gambar 2. Use Case Diagram Nazwa Wedding Organizer

Dari gambar 2 di atas merupakan perancangan use case diagram Nazwa Wedding Organizer. Pada perancangan use case diagram ini terdapat 2 aktor yang saling berhubungan. Dari gambar di atas menjelaskan bahwa Admin Login terlebih dahulu, setelah berhasil login, Admin dapat mengupdate profile, setelah itu Admin dapat mengelola menu yang terdapat di halaman Admin yaitu berupa : menu produk, menu agenda, menu member, menu sewa, menu konten halaman, menu kontak info, menu pesan masuk, dan menu laporan. Kemudian sebelum User melakukan pemesanan, User harus registrasi, setelah berhasil regsitrasi User dapat login serta mengupdate profile nya. Setelah itu, User dapat melihat agenda acara kemudian melihat petunjuk pemesanan, setelah itu User dapat melakukan pemesanan produk dan pembayaran produk, jika ada keperluan User dapat mengirimkan pesan kepada Admin dan Admin akan menerima pesan. 


\subsection{Activity Diagram}

Activity diagram digunakan untuk menggambarkan kegiatan-kegiatan yang ada di dalam suatu sistem. Agar dapat lebih memahami tentang sistem yang akan dibuat, maka perlu dibuatkan rancangan activity diagram pada sistem yang akan di buat. Berikut merupakan activity diagram Sistem Informasi Manajemen Nazwa Wedding Organizer

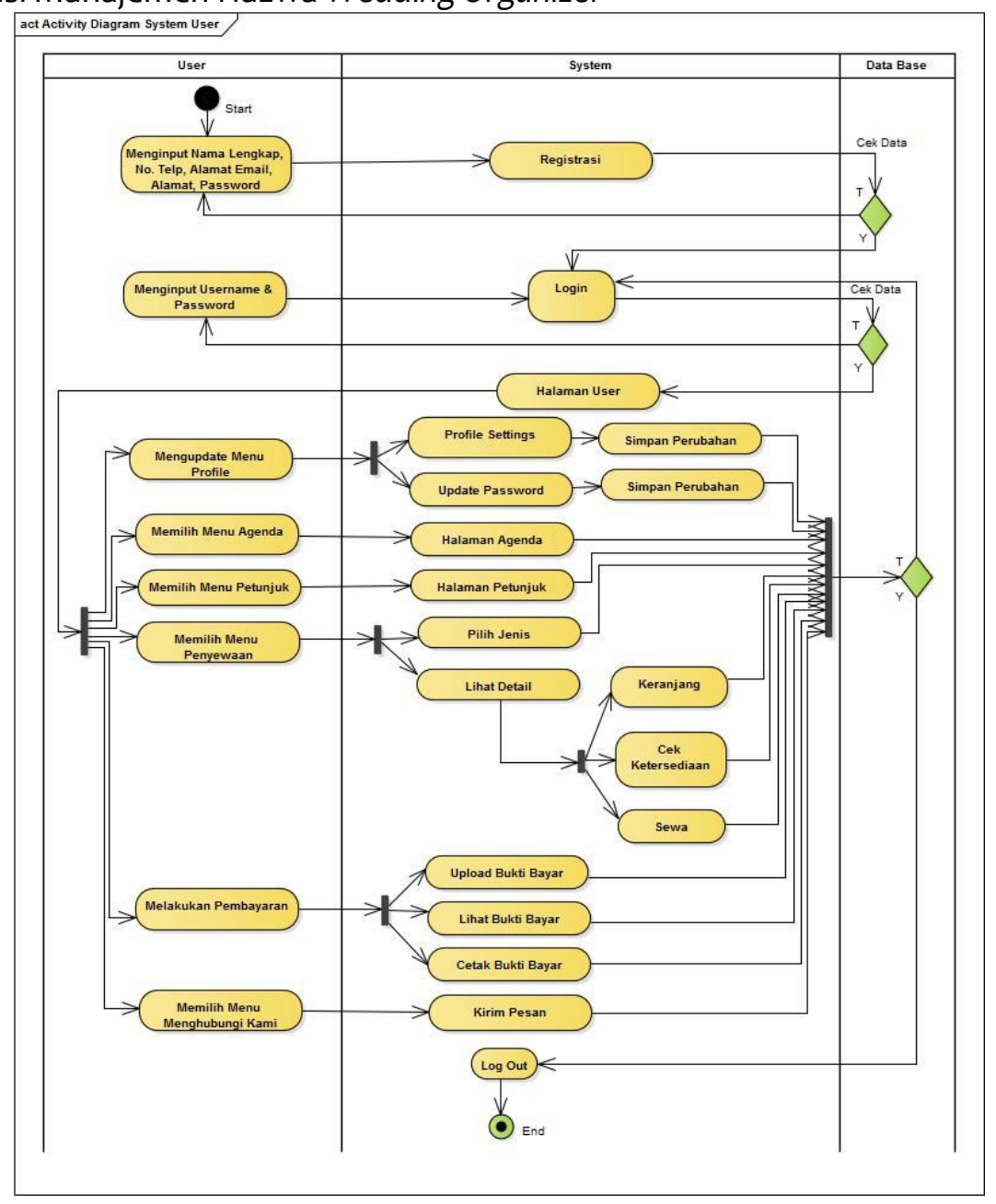

Gambar 3. Activity Diagram User

Dari gambar 3 di atas merupakan perancangan activity diagram pada User. Pada perancangan activity diagram di atas menjelaskan bagaimana proses aktivitas yang di lalui User dalam menggunakan sistem. Pertama, User menginput Nama Lengkap, No. Telp, Alamat Email, Alamat, Password untuk registrasi, kemudian sistem mencek data jika data yang di inputkan benar, maka User bisa login, tapi jika tidak benar maka User akan kembali ke halaman input data registrasi. Jika User sudah berhasil registrasi, maka User bisa login dengan menginputkan data Username dan password yang sudah terdaftar, kemudian sistem akan mencek data yang telah di inputkan, jika data benar maka login berhasil dan akan masuk ke halaman utama User, tapi jika tidak benar maka akan kembali ke halaman input data login. Selanjutnya, jika User telah berhasil login dan telah masuk ke halaman utama User, User dapat melakukan aktivitas mengupdate menu profile yang terdiri dari : (update profile settings dan update password), lalu User dapat memilih menu agenda untuk melihat agenda acara pada wedding organizer, User dapat memilih menu petunjuk untuk melihat petunjuk pemesanan, User dapat memilih menu penyewaan yang terdiri dari : (pilih jenis dan lihat detail produk, kemudian memasukkan ke keranjang sewa, cek ketersediaan produk, jika tersedia maka User bisa memilih sewa), User dapat melakukan pembayaran yang terdiri dari : (upload bukti bayar, lihat bukti bayar, cetak bukti bayar, terakhir User dapat memilih menu menghubungi kami untuk mengirim kan pesan ke Admin. Maka aktivitas pada User selesai. 


\subsection{Squence Diagram}

Menggambarkan kolaborasi dinamis antar sejumlah object. Kegunaannya untuk menunjukkan rangkaian pesan yang dikirim antar object juga interaksi antar object. Sesuatu yang terjadi pada titik tertentu dalam eksekusi sistem.

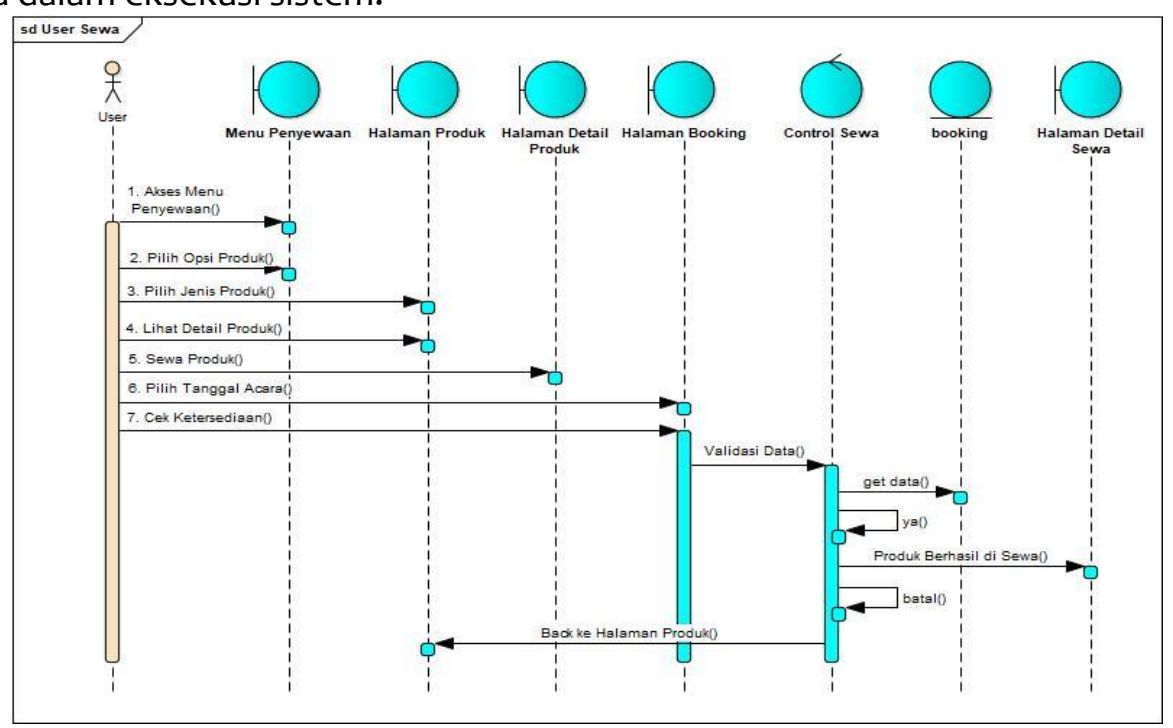

\section{Gambar 4. Sequence Diagram User Sewa}

Dari Gambar 4 di atas di jelaskan bahwa User harus mengakses menu penyewaan terlebih dahulu, lalu pilih opsi produk, kemudian User pilih jenis produk pada halaman produk, lalu lihat detail produk pada halaman produk, kemudian pilih sewa produk pada halaman detail produk, selanjutnya User memilih tanggal acara, lalu User pilih cek ketersediaan produk, maka sistem akan memeriksa apakah data yang dimasukkan valid atau invalid. Jika data valid maka produk berhasil di sewa, tapi jika data invalid maka User akan kembali lagi ke halaman produk.

\subsection{Class Diagram}

Class Diagram pada Nazwa Wedding Organizer dapat di lihat pada gambar di bawah ini :

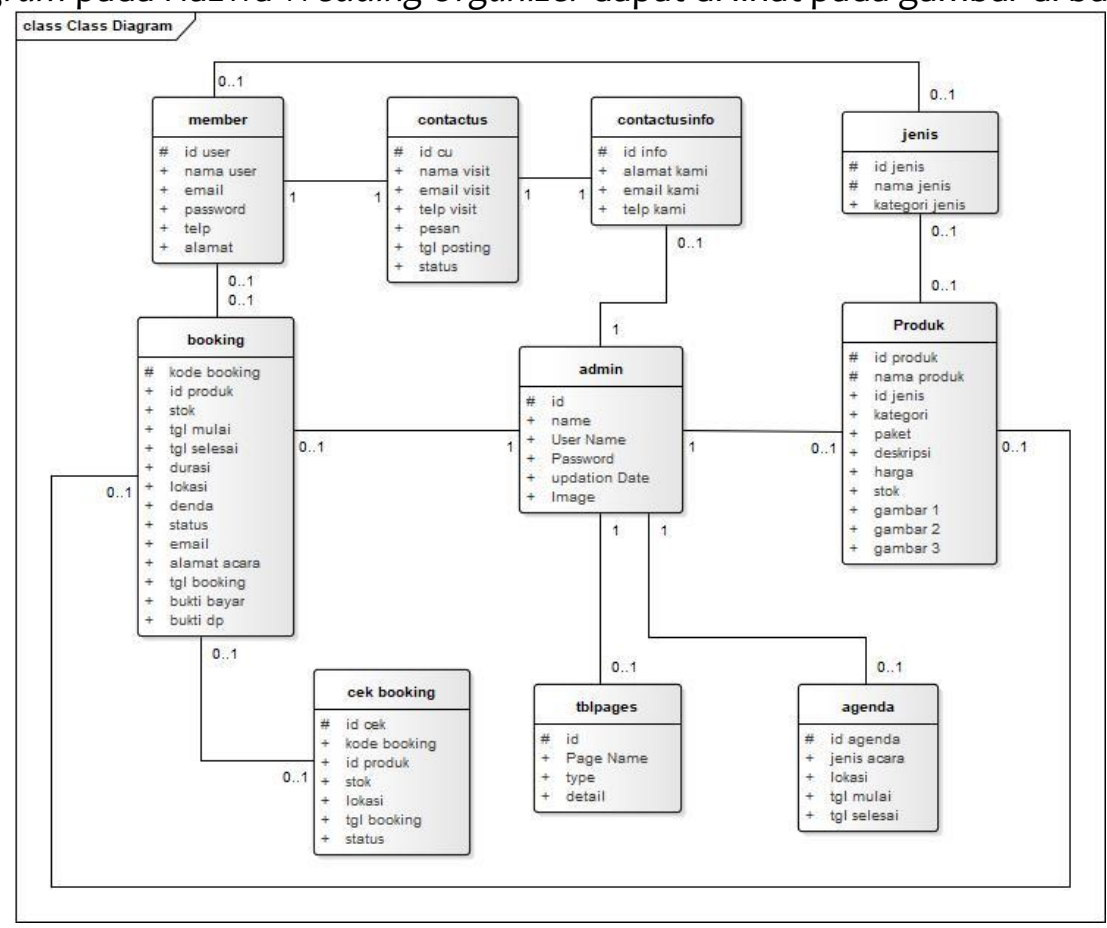

Gambar 5. Class Diagram Sistem Informasi Manajemen Nazwa 
Dari gambar 5. di atas dapat di jelaskan bahwa dalam pembuatan sistem informasi manajemen nazwa wedding organizer memiliki beberapa database sebagai tempat penyimpanan data yaitu member, Admin, contact us, contact us info, jenis, produk, booking, cek booking, tbl pages, agenda.

\subsection{Physical Data Model}

Physical data model pada Nazwa Wedding Organizer dapat di lihat pada gambar di bawah ini :

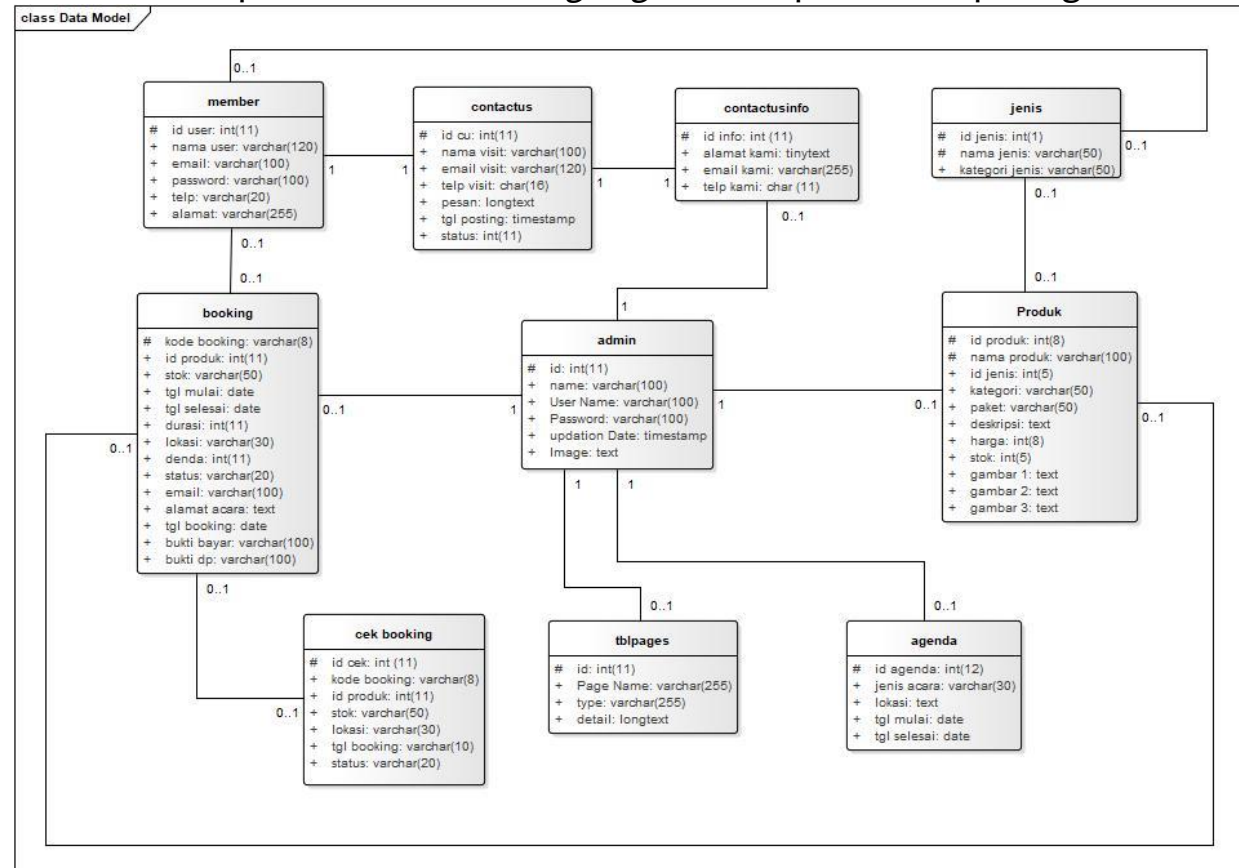

Gambar 6. Physical Data Model Sistem Informasi Manajemen Nazwa

Dari gambar 6 di atas dapat di jelaskan bahwa dalam pembuatan Sistem Informasi Manajemen Nazwa Wedding Organizer ini memiliki beberapa database sebagai tempat penyimpanan data yaitu member, Admin, contact us, contact us info, jenis, produk, booking, cek booking, tbl pages, agenda. Di dalam database tersebut terdapat atribut dan operasi yang menjadi aksi di dalam database Sistem Informasi Manajemen Nazwa Wedding Organizer ini.

\subsection{Deployment Diagram}

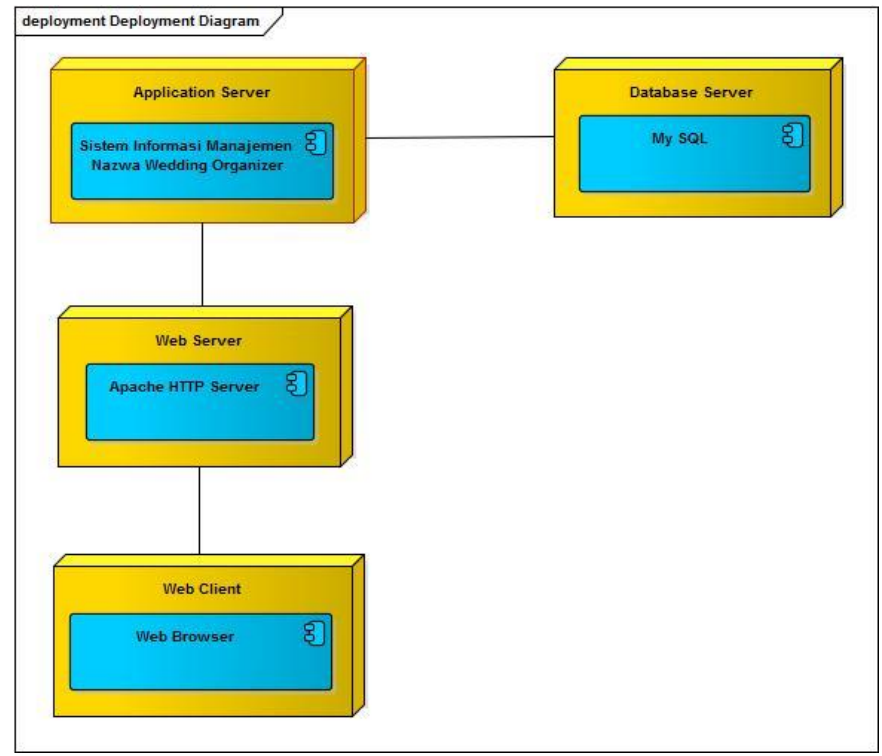

Gambar 7. Diagram Deployment 
Dari gambar 7 di atas memberikan gambaran dari arsitektur fisik perangkat lunak,perangkat keras, dan artepak dari sistem. Deployment diagram dianggap ujung spektrum dari kasus pengguna, menggambarkan bentuk dari sistem yang bertentangan dari gambar konseptual dari pengguna dan perangkat berintegrasi dengan sistem.

\subsection{Hasil Implementasi}

Pada sistem informasi manajemen nazwa wedding organizer berbasis web terdapat menumenu yang dikelola oleh Admin dalam sistem, sebelum mengelola Admin melakukan login terlebih dahulu, setelah berhasil loggin, Admin dapat mengelola beberapa menu yang terdiri dari Menu Dashboard, Menu Sewa (Input Data Sewa, Menunggu Pembayaran, Down Payment, Menunggu Konfirmasi, Pengembalian, Data Sewa), Menu Produk (Data Jenis, Data Produk), Menu Agenda, Menu Member, Menu Pesan Masuk, Menu Kelola Halaman, Menu Kontak Info, Menu Laporan. Adapun penjelasan dari beberapa proses yang dikelola olah Admin sebagai berikut :

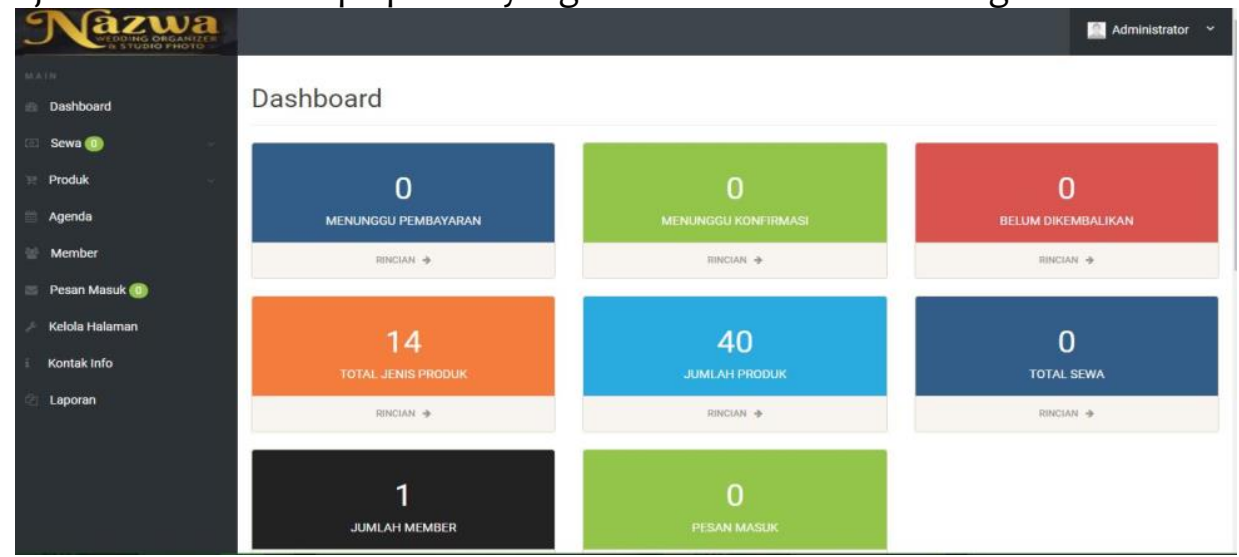

\section{Gambar 8. Tampilan Dashboard pada Admin jika telah berhasil login}

Dari gambar 8 di atas merupakan tampilan jika login berhasil dilakukan, maka akan masuk kedalam menu dashboard.

Menu Produk digunakan Admin untuk mengelola produk yang disediakan oleh nazwa wedding organizer. Admin akan mengelola data jenis produk dan data produk. Adapun tampilan yang ada di dalam Menu Produk seperti yang terdapat pada gambar 9 berikut :

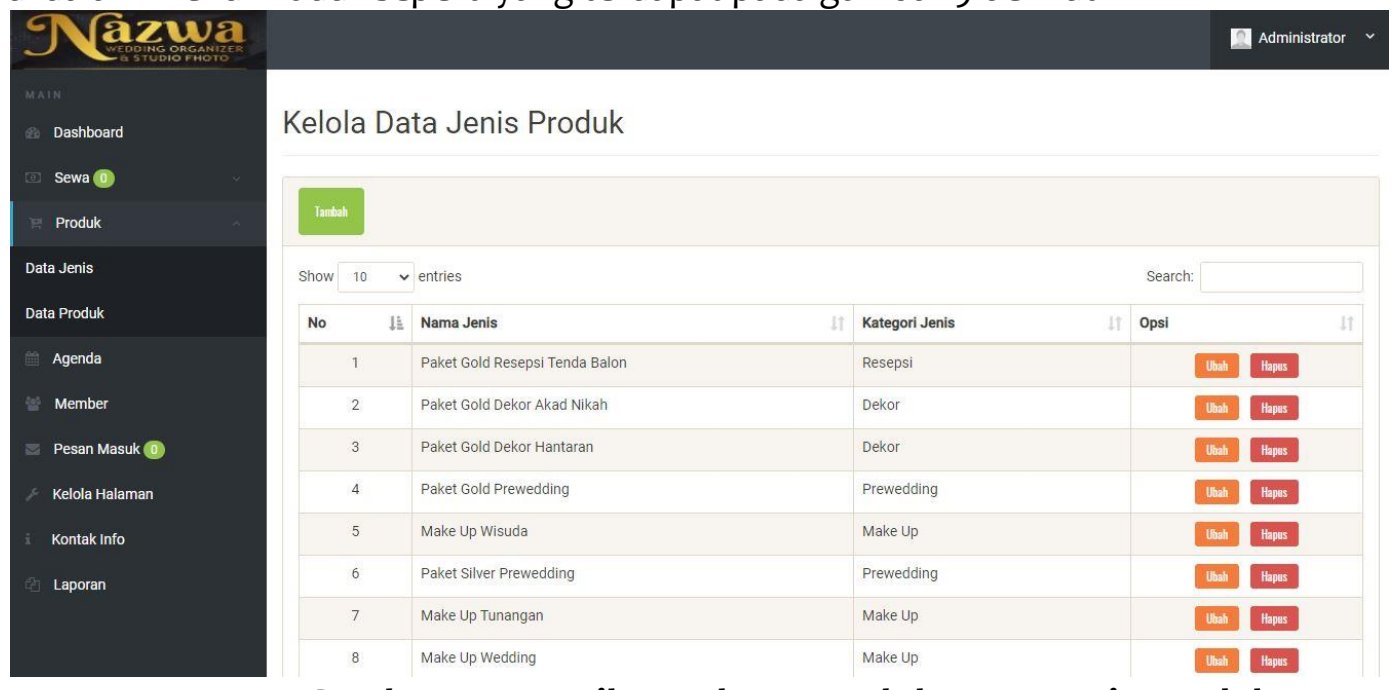

Gambar 9. Tampilan Halaman Kelola Data Jenis Produk

Dari gambar 9 di atas merupakan tampilan halaman kelola data jenis produk. Admin dapat mengubah atau menghapus data tersebut. 
Menu Penyewaan merupakan menu yang terdapat pada halaman User. User dapat memilih produk yang ingin di pesan. Adapun tampilan yang ada di dalam Menu Penyewaan seperti yang terdapat pada gambar 4.16 berikut :

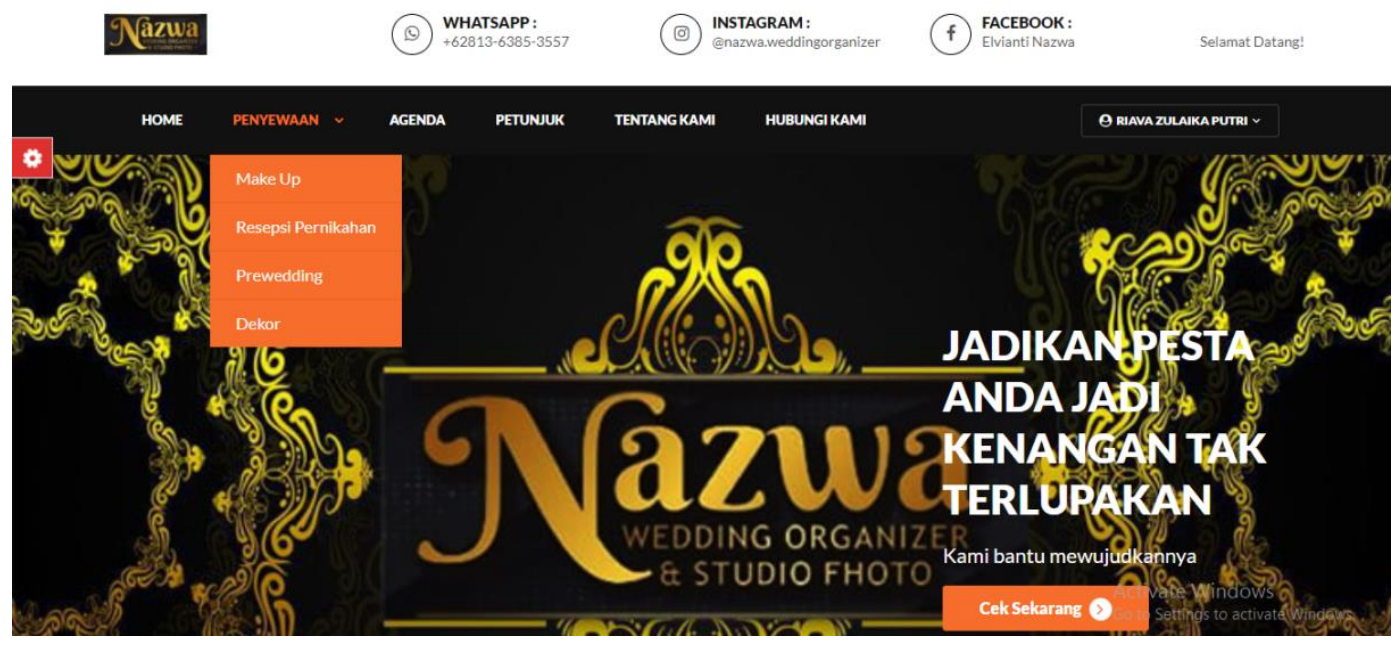

Gambar 10. Tampilan Halaman Menu Penyewaan

Dari gambar 10 di atas merupakan tampilan halaman pada menu penyewaan yang di dalamnya terdapat jenis-jenis produk yang disediakan mulai dari make up, resepsi pernikahan, prewedding, dekor.
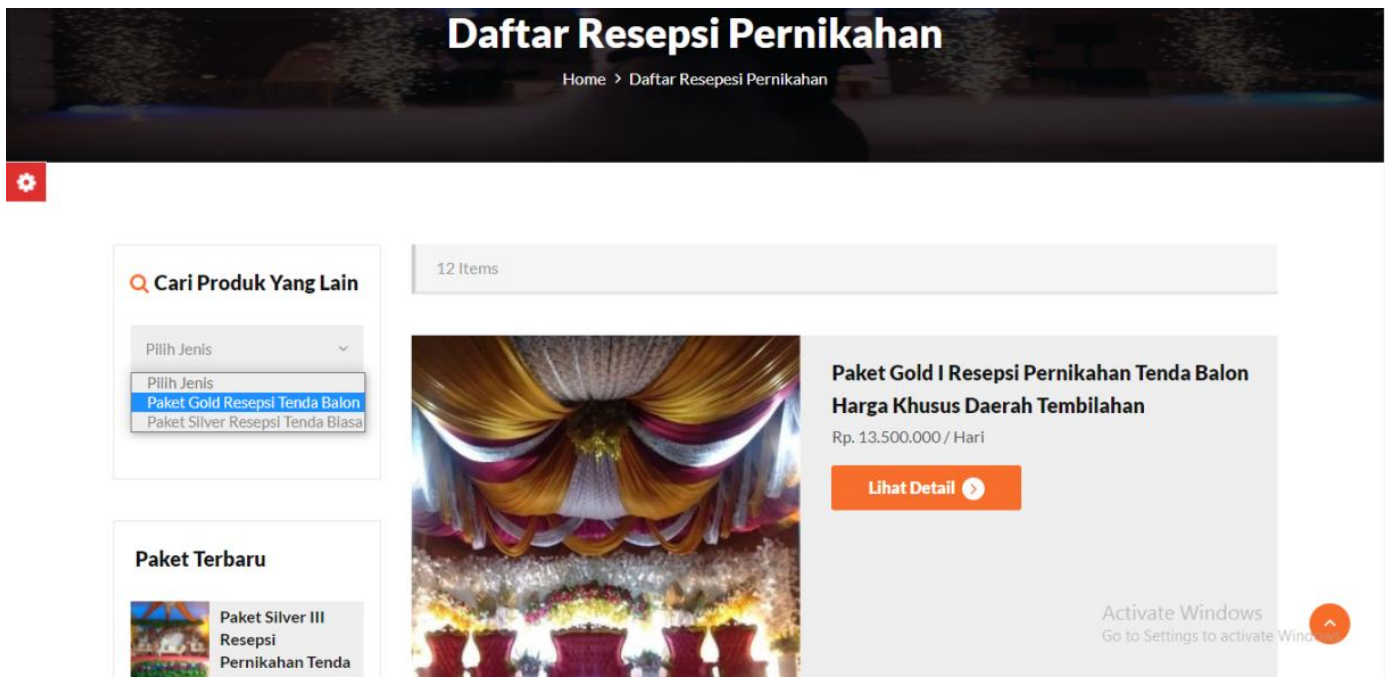

Gambar 11. Tampilan Halaman Produk

Dari gambar 11 di atas merupakan tampilan halaman produk pada menu penyewaan. User dapat memilih jenis produk dan melihat detail produk.

\section{PENUTUP}

\subsection{Kesimpulan}

Sistem Informasi Manajemen Nazwa Wedding Organizer Berbasis Web adalah :

Hasil penelitian telah dibangun Aplikasi Sistem Informasi Manajemen Nazwa Wedding Organizer Berbasis Web. Sistem ini dapat memberikan informasi mengenai produk yang tersedia dan juga sebagai sarana penyewa dalam melakukan pemesanan online melalui website. Sistem ini dapat digunakan sebagai sarana pihak nazwa wedding organizer dalam mengelola data, merekap laporan pemesanan. Sistem ini sebagai sarana pihak nazwa wedding organizer dalam mengelola agenda acara sehingga tidak terjadi bentrok tanggal antara penyewa satu dan penyewa lainnya. Aplikasi Sistem Informasi Manajemen Nazwa Wedding Organizer menghasilkan output berupa 
lembar rekap laporan data pemesanan penyewa, lembar nota pemesanan penyewa dan lembar bukti pembayaran penyewa.

\subsection{Saran}

Dalam penerapan sistem yang baru peneliti ingin mengemukakan beberapa saran agar Sistem Informasi Manajemen Nazwa Wedding Organizer bisa menjadi lebih baik diantaranya :

Jika Sistem Informasi Manajemen Nazwa Wedding Organizer ini sudah berjalan, diperlukan pemeliharaan dan dilakukan evaluasi secara berkala terhadap sistem. Perlu diadakannya pelatihan kepada pengguna (User) yang akan menggunakan sistem informasi ini, agar bisa digunakan dan dimanfaatkan dengan baik. Diharapkan untuk masa yang akan datang sistem informasi manajemen nazwa wedding organizer ini bisa dikembangkan lagi sesuai kebutuhan.

\section{REFERENSI}

[1] D. Y. Prasetyo And Program, "Penerapan Metode Utaut (Unified Theory Of Acceptance And Use Of Technology) Dalam Memahami Penerimaan Dan Penggunaan Website Kkn Lppm Unisi," J. Sist., Vol. 6, No. 2, Pp. 26-34, 2017.

[2] Hamdi, Usman, And Samsudin, "Perancangan Sistem Informasi Geografis Pemetaan Taman Di Kabupaten Indragiri Hilir Berbasis Web," J. Sist., Vol. 7, No. 2, Pp. 78-86, 2018.

[3] L. Nilhuda, "Sistem Informasi Manajemen," Vol. 03, No. 02, Pp. 80-87, 2019, Doi: 10.31227/Osf.lo/V7zqx.

[4] R. W. Ss, H. S. Pratiwi, And H. Muhardi, "Rancang Bangun Aplikasi Wedding Organizer Di Kota Pontianak Berbasis Web," J. Sist. Dan Teknol. Inf., Vol. 5, No. 3, Pp. 3-7, 2017.

[5] M. Destiningrum And Q. J. Adrian, "Sistem Informasi Penjadwalan Dokter Berbassis Web Dengan Menggunakan Framework Codeigniter (Studi Kasus: Rumah Sakit Yukum Medical Centre)," J. Teknoinfo, Vol. 11, No. 2, P. 30, 2017, Doi: 10.33365/Jti.V11i2.24.

[6] D. Pratmanto, A. Fatakhudin, And I. Pendahuluan, "Rancang Bangun Sistem Informasi Pemesanan Paket Pernikahan Dan Preweding Berbasis Web," Vol. 3, No. 2, Pp. 68-76, 2017.

[7] J. Sasongko And D. A. Diartono, "Rancang Bangun Sistem Informasi Manajemen Surat," Ranc. Bangun Sist. Inf. Manaj. Surat Jati, Vol. Xiv, No. 2, Pp. 137-145, 2009, [Online]. Available: Jati@Unisbank.Ac.Id, Dwiagus@Unisbank.Ac.Id.

[8] D. Agustin And A. U. Bani, "Perancangan Sistem Informasi Jasa Wedding Organizer Pada Cv . Boganesia Jaya Berbasis Web," Vol. 2020, No. 2, Pp. 15-25, 2020.

[9] G. W. Sasmito, "Penerapan Metode Waterfall Pada Desain Sistem Informasi Geografis Industri Kabupaten Tegal," J. Inform. Pengemb. It, Vol. 2, No. 1, Pp. 6-12, 2017.

[10] N. Huda, "Analisis Kinerja Website Pt Pln (Persero) Menggunakan Metode Pieces," Sistemasi, Vol. 8, No. 1, Pp. 78-89, 2019, Doi: Doi: Https://Doi.Org/10.32520/Stmsi.V8i1. 